\section{Reinaldo Guimarães}

Secretaria de Ciência, Tecnologia e Insumos Estratégicos. Ministério da Saúde. Brasília, DF, Brasil

\section{Correspondence:}

Reinaldo Guimarães

R. Sacopã, 191 - Apto. 102

Lagoa

22471-180 Rio de Janeiro, RJ, Brasil

E-mail: reinaldo.guimaraes47@gmail.com

Received: 8/16/2010

Approved: 14/10/2010

Article available from: www.scielo.br/rsp

\section{Challenges of postgraduate human health programs in Brazil}

\begin{abstract}
Recognition for the growing role of extra-academic demands and players in the dynamics of human resource training for the market and, in particular, for research is discussed. Their synergies with the movement towards maturation of the sectoral system of healthcare innovation and with the priorities of the Sistema Único de Saúde (Brazilian National Health System) are discussed. The methodological adequacy of the process for evaluating these trends used by the Coordenação de Aperfeiçoamento de Pessoal de Nível Superior (Coordination Office for Advancement of University-level Personnel) is analyzed. In a general manner, these trends mean adding new indicators for technological and social productivity to the predominantly academic criteria that already exist. The continuation and deepening of ongoing initiatives aimed at bringing in new formats for postgraduate programs and courses and new courses customized for the demands of the extra-academic market, among other markets, either of a social or technological-business nature, are discussed. In addition, the deepening of initiatives for stimulating postdoctoral training work, which is scarce in Brazil, is discussed.
\end{abstract}

DESCRIPTORS: Health Postgraduate Programs. Education, Graduate, trends. Health Manpower. Education, Public Health Professional. Higher Education Policy.

\section{CONTEXT}

The following statement is extracted from the introduction to the Fourth National Plan for Postgraduate Programs (PNPG, 2005-2010): "The data available demonstrate especially that Brazilian scientific and technological research activity basically takes place within the national system of postgraduate programs". a

This statement can be confirmed in several ways. Among these, it can be shown that around $95 \%$ of the holders of research productivity bursaries from the Conselho Nacional de Desenvolvimento Científico e Tecnológico $(\mathrm{CNPq})$ teach in postgraduate programs. ${ }^{b}$ Furthermore, the growth in Brazilians' contributions published in indexed journals during the 1980s, 1990s and this first decade of the new century matches the growth rate in doctoral programs over the same period. In addition, inversely, it can be seen that in the expanded sample of the Second Technological Innovation Survey of the Instituto Brasileiro de Geografia e Estatística (IBGE, 2003), which represents 72,005 Brazilian manufacturing

a Ministério da Educação. Coordenação de Aperfeiçoamento de Pessoal de Nível Superior. Plano Nacional de Pós-graduação - PNPG 2005/2010. Brasília; 2010 [cited 2010, Jun 30]. Available from: http://www.capes.gov.br/sobre-a-capes/plano-nacional-de-pos-graduacao.

bAPES, 2006 - Ricardo Lourenço, personal communication. 
companies with almost five million employees, it was found that only 6,200 individuals with university-level education were involved full-time in internal research and development (R\&D) activities. ${ }^{\mathrm{c}}$ To discuss the future of health-related postgraduate programs, it is important to project the above statement from the Fourth PNPG and examine it in a judicial manner.

Science and technology policies in Brazil are going through a new long cycle that started in 1999 with the creation of sectorial funds. The changes followed on from actions by the federal government, in which industrial, technological, foreign trade and production development policies were drawn up, along with transverse sectorial fund programs, the Innovation Law and its regulatory decree, and emphasis on the Banco Nacional do Desenvolvimento Econômico e Social (BNDES) in projects with important development and innovation components, as shown by the support program for the healthcare industry (Pro-Farma), ${ }^{\mathrm{d}}$ Law no. 11,196 and approval for the economic support model for companies through the Studies and Projects Funding Agency (FINEP). The Petrobras research and development support program (R\$ 1.7 billion per annum) deserves to be mentioned because of its size, ${ }^{\mathrm{e}}$ along with the considerable increase in the dynamism of various state institutions for research support. However, perhaps the clearest expression of this new stage in science and technology policies is the evolution of the budgets destined for the Fundo Nacional de Desenvolvimento Científico e Tecnológico (FNDCT). After becoming irrelevant over most of the 1990s, there is a budget proposal for 2011, amounting to $\mathrm{R} \$ 3.6$ billion. ${ }^{\mathrm{f}}$ The growth in the budgets of CNPq, the Coordenação de Aperfeiçoamento Pessoal de Nível Superior (CAPES) and some state research support agencies (Fundação de Amparo à Pesquisa do Estado de Minas Gerais FAPEMIG - and Fundação de Amparo à Pesquisa do Estado do Rio de Janeiro - FAPERJ, in particular) should also be recorded. Another important indicator for understanding this new stage is the strengthening of cooperation between institutions, especially between federal bodies and between these and state bodies with research support and sectorial policy responsibilities. Over the last few years, players that traditionally did not have an active role in science and technology policies have come into the picture, such as the technology and innovation component of the National Defense Strategy (Ministry of Defense) and the establishment of a science, technology and innovation policy by the Ministry of Health.
In summary, from this set of changes and paths, three points can be emphasized: (1) an increase in induction capacity, in that priority components defined by players within and, especially, outside the scientific community have been added to the perspective of scientific merit; (2) emphasis on the technological component and on seeking innovation, thereby looking towards shifting the traditional balance seen in research conducted in Brazil; and (3) strengthening of the business component, through envisaging associations between companies and research groups and institutions, and more recently, directly stimulating development and innovation within companies.

It is possible that science and technology policies are today pointing in the right direction and have entered the small Brazilian list of what is usually called "State policies".

However, this has not yet happened with policies directed towards productive innovation. Despite the abovementioned initiatives, there is no evidence available of any significant change in companies' innovation rates, as shown by the statistics from various versions of the Industrial Technological Innovation Survey (PINTEC/IBGE) within the field of manufacturing industry. The rate of incorporation of technology developed in Brazil into the reported innovations is small. ${ }^{\mathrm{g}}$

In any event, the positive impact from the reforms should be reflected in the institutional organization of the research system, starting with the institutions responsible for the greatest proportion of the research: the public universities. However, the ossification of the public administration within the three spheres of government (in particular in the universities and the funding institutions themselves) may be fatal with regard to full achievement of the objectives of science and technology policy changes, with their new normative and financial tools.

One of the most striking traits in the institutional development of research in Brazil has been the crises experienced by many Brazilian research institutions. After the Second World War, the prestige of the American model of Research Universities occupied a major part of the scenario, and institutes became weakened. After the creation of the postgraduate program policy (in 1965), the strategy followed by several of them with a view to survival was to adopt universitylike characteristics, including departmentalization (through the university reform of 1968) and, especially,

\footnotetext{
c Instituto Brasileiro de Geografia e Estatística. Pesquisa Nacional de Inovação - 2003. Brasília; 2003 [cited 2005, Jun 15]. Available from: http://www.pintec.ibge.gov.br/

${ }^{d}$ The revitalization of the BNDES Technological Fund (Funtec), with a substantial increase in its endowment, should also be mentioned.

e Pró-inovação Tecnológica. [cited 2010, Apr 7]. Available from: http://www.protec.org.br/noticias.asp?cod=1794

${ }^{f}$ The budget of the FNDCT in the Annual Budget Law for 2010 was R\$ 3.1 billion.

g According to the various versions of the IBGE's Industrial Technological Innovation Survey, around $60 \%$ of the innovations in companies that reported them related to purchases of new machines.
} 
investment in postgraduate programs. The research institutes that, for a variety of reasons, did not adopt this strategy experienced a deepening crisis, as in the cases of several state research institutes in the fields of healthcare and agriculture in the state of São Paulo and the Instituto Nacional de Tecnologia. The great exception to this general rule was the Empresa Brasileira de Pesquisa Agropecuária (EMBRAPA), which was created in 1973. The strategy of becoming academic institutions was successful in many cases, but it had the cost that these institutions lost their links with their original missions to varying degrees, as occurred with the Oswaldo Cruz Foundation and with institutes that were at that time linked to CNPq (for example, the Centro Brasileiro de Pesquisas Físicas).

Another likely consequence of the institutional reorganization caused by the reforms may be a resurgence of research institutions guided by missions and without links to academic attributes, to a greater or lesser extent. This is because in a reform of science, technology and innovation policies aimed at the three dimensions of induction, technology-based innovation and companies, the architecture of institutes tends to be more functional and can be shaped to the policy guidelines more rapidly. Although this does not threaten the hegemonic university-academic model, it should be noted because of the importance that some institutes may have within a scenario of intensive stimulation of technology and innovation. It is feasible for the two institutional models to exist side-by-side, and this is even seen in the United States, from which the Brazilian institutional framework was inspired. There, alongside the major research universities, important research institutes exist in the form of national laboratories or institutes.

A recent initiative by the Ministry of Science and Technology (MCT) anticipated this possible institutional adjustment. With coordination by $\mathrm{CNPq}$, the program for national science and technology institutes has announced an intermediate and conciliatory model between the academic world and the world of research institutes. Ten years ago (2000), the Fundação de Amparo à Pesquisa do Estado de São Paulo (FAPESP) went through a similar experience with the creation of research, innovation and dissemination centers. Both in the MCT and in the FAPESP program, activities relating to research on human health are present. Among the national science and technology institutes, human health is the central theme in 41 of the 120 projects approved and in five of the eleven research, innovation and dissemination centers, along with another three in which the sector is present. With regard to companies, despite the findings from the second PINTEC, mentioned earlier, which showed that there had been a small decline in the rate of innovation within Brazilian manufacturing industry, in relation to the previous survey, it can be expected that once the new BNDES and FINEP (and FAPESP) programs have come into effect, companies will increase the research and development activities, along with their innovation actions. Like in the universities and research institutes, this would be expected to occur with varying intensities and at differing times, between industrial sectors and geographical regions. The creation of technological centers in several states (São Paulo, Minas Gerais, Bahia, Rio Grande do Sul and others), albeit still at an incipient stage, foreshadows this development.

\section{Relationship between research and postgraduate programs}

Over the medium term, the adjustments resulting from the reform may turn the extract from the introduction to the Fourth PNPG, mentioned earlier, into a relative statement. In other words, it is possible to speculate that there could be an increase in research activity "outside" of the national system of postgraduate programs over the coming years. If this were to occur, it would be necessary to consider the possible adjustments to Brazilian policies for postgraduate programs that would be needed to face up to this new situation. However, to discuss this affirmation, a retrospective look at recent Brazilian history is needed.

In the 1970s, Brazil increased its scientific and technological capacity. Science and technology, identified as such, were included in general economic development plans and, soon thereafter, were the subjects of sectorial plans in this country. ${ }^{\text {h }}$ The most important focus of these plans related to infrastructure construction, and the funding agent placed in charge of the support actions was the FNDCT, which was created in 1969, with management by FINEP from 1971 onwards. Between 1970 and 1979, the fund handed out around US\$ 1.5 billion, and the mean value of the projects undertaken during that period was US\$ 1.7 million. ${ }^{5}$ Through a decision by the main executor of science and technology policy at that time, one important criterion in judging the proposals presented to FINEP was whether postgraduate programs existed or whether creation of such programs concomitantly with carrying out the main research activities was planned. Between 1969 and 1979, the number of postgraduate courses leapt from 125 to 974 . The number of doctoral programs went up from 32 to 257 . From 1984 onwards, another support program was introduced in addition to the FNDCT (and came to occupy its place in practice). The Scientific and Technological Development Support Program (PADCT) was jointly funded by the Brazilian

$\mathrm{h}$ This occurred starting from the Economic Development Plan of 1968 and subsequently in the Basic Scientific and Technological Development Plans of the 1970s. 
federal government and the World Bank, and FINEP was its executive secretary. It provided support for large research projects within certain fields of knowledge, in which infrastructure components and the presence of postgraduate courses were given value in the selection processes. The PADCT was in operation until 2004 but from the mid-1990s onwards, it gradually went on losing its initial characteristics.

Starting in the 1970s and continuing for another 20 years, the development of research (and particularly the factors relating to research infrastructure) was essentially a function of the expansion of the postgraduate program capacity. In other words, it can be said that from the 1970s onwards, research sought to have postgraduate programs and hence to develop. This was because the hegemonic institutional model was university-based and many of the greatest talents were (and are) in universities; and especially, because the financial support for research activities over this period, and until very recently, was firmly tied to expansion of the postgraduate program system.

The Brazilian educational policy for training human resources at postgraduate level has repeatedly been said to be successful. With a view to the future, the relationships between this policy and a research and development policy raised to the condition of a state policy, with greater emphasis on the technological and business components, need to be reexamined.

The main structural change in the system will be a gradual and growing inversion in direction in relationships between research and postgraduate programs. Once the new policy has become consolidated, it is not unreasonable to imaging that postgraduate programs should increasingly seek research. This movement going against tradition may result in an increase in what could be called "opening up" of postgraduate programs beyond the boundaries of higher education itself, thereby focusing more intensely on the country's needs in a general manner, in addition to the important mission of training qualified human resources for universities.

The main component in the mission of Brazilian postgraduate programs, which is also indicated because this was developed by CAPES, has been the capacitation of teaching staff for Brazilian universities. In a future scenario, this capacitation will come to have considerably less weight in the general mission of postgraduate programs. Instead of a situation in which three-quarters of graduates from doctoral programs work within higher education, ${ }^{7}$ a higher proportion (even if not a majority) of young adults with master's degrees and, especially, doctorates will go out into the market of non-academic professions, to research institutes and, particularly, companies. If the world outside of academia starts to have greater importance in forming the demand for graduates at postgraduate level, it would be expected to have greater influence in proposals for setting the requirements for the people that were sought. This would seem to be one of the vectors for the future of postgraduate programs in Brazil, if not the main vector.

\section{Research, postgraduate programs and demand}

One important characteristic of the present scientific scenario, and which will become much more intense in the coming years, is the growth in investigation methods that are known generically as strategic research. In this, the investigation associates the advancing of knowledge with considerations regarding early use of the results attained. ${ }^{10}$ The need for mediation (also at an early stage) by players from outside of the world of science is common and increasingly relevant.

The diagnosis that the development of science and technology policies in Brazil was strongly based on "provision" of knowledge is longstanding and well established. One of the reasons for the predominance of this path was the tributary relationship of research to postgraduate programs, as presented earlier. Since academia is the canonical space of postgraduate programs, in which historically, a certain degree of autonomy in relation to society's demands has been accepted (as an expression of academic freedom), the terrain was propitious for developing research centered on the provision of knowledge.

If the relationships between postgraduate programs and research start to change, and if strategic research (more intensely governed by demands) gains greater space, the impact of this new environment may be enormous. The process may present different speeds according to the field of knowledge, governed by the extent to with which society's demands can be met through scientific and technologically-based knowledge. This trend may be shown not only in the field of engineering, healthcare or other fields with a strong technical basic. In the humanities in general and in the natural sciences, a view from outside academia (but not an anti-academic view) may be important, for example in evaluating projects. There will be a time when the participation of a social movement in evaluating a project in the field of studies on violence or of a business leader in the case of the project on chemistry or engineering will seem less strange.

The fields of research and postgraduate programs used by Brazilian support agencies are also constructed essentially on the basis of "provision". There does not seem to be any dispute regarding the role that some

iThere are, of course, other determinants of the "provision" model. For example, the pattern of Brazilian industrialization was associated with and subordinated to world industrial centers. These other determinants will not be discussed here. 
technologies that are directly derived from state-ofthe-art scientific knowledge may come to perform over the next few years. In particular, three technological fields are usually cited: biotechnologies, nanotechnologies and information technologies. These three fields have in common with each other that they are among the most dynamic fields in terms of the critical mass involved and the financial resources invested, even though they are research fields at premature stages of development of their cycles.

One question that has to be asked is: what identity would these three fields present in the CAPES evaluation processes? Their identities are almost secret, given that they are embedded in a dozen or more fields of knowledge scattered across the traditional taxonomic tree that is in use. Fields of research can be organized according to more than one criterion. In some cases, it is possible to identify fields of knowledge grounded in a very well determined theoretical-methodological corpus, as in the cases of physics, physiology, chemistry, biology or sociology. In other cases, the fields of knowledge are differentiated according to disciplinary criteria, such as medicine, engineering, public health, economics and law. Finally, in other cases, it is not possible to differentiate between fields of research using theoretical-methodological criteria or using disciplinary criteria. In these cases, the taxonomy is based on teleological criteria, i.e. sustained through the purpose of the research. Biotechnology, nanotechnology and information technology are examples of the latter. Fields of research are organized around applications of various disciplines and theoretical-methodological references. Organizations based on theoretical-methodological or disciplinary criteria produce hierarchies across large fields of knowledge. Taxonomies based on criteria of purpose produce hierarchies of sectors and subsectors of activities or applications. In Brazil, the knowledge tree most used is coordinated by CNPq. It has the virtue of having national legitimacy and, with little variation, it is used by federal and state funding agencies, along with most teaching and research institutions. However, it is insufficient for fields of research that are organized according to sectors of application or activity and have already provided all the applications possible.

Over the last few years, with the aim of addressing the problem generated through the growth in demand for heterodox programs in terms of the traditional taxonomy, CAPES has sought to create the alternative of fields described as "multidisciplinary". This solution seems to be insufficient, albeit understandable from a tactical point of view, since it treats promising proposals (that are mostly guided by demand) as deviants from the canonical taxonomy (which is mostly guided by provision). The "multidisciplinary" fields, as named using the CAPES operational statutes, are insufficiently grounded, given that they are organized according to exclusion criteria. In other words, programs are allocated to these fields because they do not fit in the traditional areas, and not through positive criteria within the theoretical-methodological or disciplinary framework. At a more rigorous analytical level, it can be said that things are considered to be interdisciplinary when they are not so. The challenge seems to be to redefine the borders of what should in fact be taken as such.

It is not unreasonable to suppose that, a decade from now, programs organized according to sectorial patterns will be more numerous than they are today and may make the difference in terms of research that is more strongly organized according to demand. The organization of fields of evaluation according to the current standards may become unacceptable. This is an essential topic, for example for the development of the main evaluation tool that currently exists: the periodic assessment of programs coordinated by CAPES.

It is well known that doctoral students and postdoctoral trainees play an essential role that underpins research work. As observed earlier, the variable that best fits the widely commemorated increases in Brazilian presence in studies indexed in international databases is the growth in the number of doctoral students completing their studies. If on the one hand, the curve of the numbers of individuals graduating from doctoral programs over the last two decades is very satisfactory, the time has perhaps come to give greater stimulation to postdoctoral training, both in Brazil and abroad. There is a great lack of postdoctoral training programs in Brazil, compared with the American statistics. Table 1 presents a comparison over recent years between Brazil and the United States regarding the numbers of individuals graduating from doctoral programs (sciences and engineering) and the numbers of participants in postdoctoral training programs. It shows the lack of postdoctoral training programs in Brazil. The distribution of postdoctoral training programs according to fields of knowledge (in the classification of the National Science Foundation) shows that biological sciences represent $38.5 \%$ of all postdoctoral positions and health-related sciences (medicine and other life sciences) plus psychology represent $31.1 \%$ of the total. Considering that a significant proportion of what is categorized as biological sciences is directly linked to human health, it is likely that this sector is the one most represented among American postdoctoral positions. ${ }^{j}$

One of the important points to discuss is combination of the stimulus given through study bursaries (which, as laid down by the National Postdoctoral Program

i Science \& Engineering Indicators 2010 - National Science Foundation, at http://www.nsf.gov/statistics/seind10/c2/c2s4.htm for postdoctoral positions and http://www.nsf.gov/statistics/seind10/c2/c2s3.htm\#s5 for graduates from doctoral programs. 
Table 1. Graduates from doctoral programs and participants in postdoctoral programs. Brazil and the United States, 2006-2009.

\begin{tabular}{|c|c|c|}
\hline Students & Brazil & United States \\
\hline $\begin{array}{l}\text { Graduates from doctoral } \\
\text { programs }(\mathrm{A})\end{array}$ & $10,701^{a}$ & $40,980^{b}$ \\
\hline Postdoctoral trainees (B) & $1,200^{c}$ & $49,261^{b}$ \\
\hline $\mathrm{A} / \mathrm{B}$ & 8.92 & 0.83 \\
\hline
\end{tabular}

a 2008, Coordination Office for the Advancement of University-level Personnel (CAPES), Ministry of Education

b Estimate (PNPD 2009 announcement + 30 Postdoctoral SUS bursaries) $\times 2$

c National Science Foundation (NSF) data for postdoctoral trainees are from 2006. For graduates from doctoral programs, the data are from 2007

NSF: National Science Foundation Science \& Engineering Indicators 2010, available at http://www.nsf.gov/statistics/ seind10/c2/c2s4.htm for postdoctoral trainees and at http:// www.nsf.gov/statistics/seind10/c2/c2s3.htm\#s5 for graduates from doctoral programs.

(PNPD), should have long duration than bursaries for doctoral programs) with specific financial support for developing the project that should be undertaken during the training program. Although still at an initial phase, the National Health-Related Postdoctoral Program of the National Health System (Postdoc/SUS) that has been developed by CAPES in collaboration with the Ministry of Health is an interesting example. CAPES offers the bursary and the Ministry of Health funds the research project. The topics selected each year for the public convocation made by CAPES are defined by the ministry within its research priorities. Postdoc/SUS is expected to last for ten years and aims to promote 150 postdoctoral training programs.

\section{Health-related research and postgraduate programs}

The twentieth century was revolutionary in several dimensions: politics, economics and scientific and technological development. The latter was the start of a movement that, from a viewpoint inside the world of science, kept physics at the forefront of scientific disciplines for decades. From a viewpoint outside of science, i.e. from the perspective of society in general, physics achieved notable visibility. Its most intense (and dramatic) expression was its principal technological product: nuclear bombs, as inaugurated over Hiroshima and Nagasaki, in 1945.

Less than ten years after these two explosions, in 1953, Crick and Watson announced the discovery of the double helix of DNA. Since then, with genetics and molecular biology in the lead, the biosciences have increasingly taken over the role in the vanguard of science that belonged to physics for most of the twentieth century.
It is not difficult to understand the implication of this revolution in the biosciences for human health: humans may be complex beings, with social and psychological traits, among others, but humanity has a structural framework that is $100 \%$ biological.

This revolution, starting in the second half of last century, has unfolded with projections in several directions, and its impact on research on human health deserves to be highlighted. Out of all the complexity in the relationships between the biological revolution and research on human health, three essential aspects can perhaps be extracted, to help in comprehending its specific features, relevance and new face.

1. The development of what Gadelha et $\mathrm{al}^{4}$ called the Healthcare Production Complex, composed of an industrial complex and a complex of services, is an analytical model for comprehending the relationships between the healthcare industry and the healthcare services that use its products and processes. Alongside the Healthcare Production Complex, there has been an explosion of activity worldwide (albeit very asymmetrical between regions), which has ended up generating a market for medications, vaccines, equipment and other industrial products that is currently valued at around US\$ 1 trillion per annum. The healthcare industry is based on scientific and technological knowledge and, along with the information industry, it is the one that proportionally has the highest investments in research and development (around 15\% of its earnings).

2. Consequently, a process of technification of individual and collective healthcare systems and practices has been taking place. The speed with which new products and processes are launched onto the market is increasing. The vast majority of these items bring with them large quantities of basic scientific knowledge and technologies derived to some extent from this. These dynamics have an impact on national healthcare systems and present problems that are increasingly difficult for the human resources acting within healthcare to solve. Healthcare workers find it increasingly difficult to keep up to date with scientific and technological developments and present growing dependence on guidance from product manufacturers. ${ }^{k}$

3. In a manner resembling the relationships between the healthcare industry and the healthcare systems, services and professionals, the relationships between the industry and health research are also far from unaffected. As will be seen later on, the most prevalent type of health research in Brazil

${ }^{\mathrm{k}}$ It is often said that the main tools for keeping physicians up to date today are visits by commercial representatives from companies and the information slips that come with medications. 
Table 2. Expenditure on human health-related research and development, according to the source of the funds. Brazil, 20032005.

\begin{tabular}{lccccc}
\hline Source of funds $^{\mathbf{a}}$ & 2003 & 2004 & 2005 & $2003-2005$ & Annual mean \\
\hline Federal government & 169.4 & 204.8 & 301.5 & 675.7 & 225.2 \\
Ministry of Health & 62.1 & 73.6 & 110.0 & 245.7 & 81.9 \\
Ministry of Science and Technology & 62.8 & 89.0 & 111.0 & 262.9 & 87.6 \\
Ministry of Education & 155.7 & 161.6 & 175.8 & 493.1 & 164.4 \\
Other ministries & 3.6 & 3.6 & 3.5 & 10.7 & 3.6 \\
State governments & 209.8 & 214.2 & 223.0 & 647.0 & 215.7 \\
Education departments & 140.5 & 140.5 & 140.5 & 421.5 & 140.5 \\
Research support foundations & 63.6 & 67.6 & 76.8 & 208.1 & 69.4 \\
Other state institutions & 5.7 & 6.1 & 5.7 & 17.4 & 5.8 \\
Public sector & 494.0 & 542.0 & 623.3 & 1659.4 & 553.1 \\
Private sector & 174.9 & 174.9 & 174.9 & 524.8 & 174.9 \\
International organizations & 13.8 & 15.6 & 21.0 & 50.4 & 16.8 \\
\hline Total & 682.7 & 732.6 & 819.2 & 2234.5 & 744.8 \\
\hline Source: Viannat & & & &
\end{tabular}

Source: Vianna et $\mathrm{al}^{12}$

a Expenditure in United States dollars of 2000.

is clinical research, which is defined as research conducted using experimental models or human observations. A good proportion of it depends on the healthcare industry in the role of research sponsor, to the point that it is not far from the truth to say that clinical research is the only type of research carried out in Brazil in which most of the decisions are made abroad. At the international level, these new relationships between the healthcare industry and the health-related scientific community have ended up generating a concept to explain them, termed translational medicine or translational research, depending on which side the observed is on. Its maxim is "from the bench to the bedside".

This seems to be the current Brazilian and worldwide situation of health-related research. It has to be borne in mind in making projections for health research and services (and for human resource training) in Brazil.

A survey conducted by the Global Forum for Health Research ${ }^{1}$ has shown that around US\$ 160 billion were spent on health-related research and development around the world in 2005. Public sources were responsible for $44 \%$ and private resources for $56 \%$ of this amount. Around $96 \%$ of all the resources came from sources in developed countries. Among the government sources (around US\$ 70 billion), a little more than half of it corresponded to the budget of the National Institutes of Health in the United States.

Paraje et al ${ }^{9}(2005)$ showed that $90.4 \%$ of the worldwide scientific and technological bibliographic production was concentrated in 42 high-income countries, and that the five most productive countries (USA, United Kingdom, Japan, Germany and France) accounted for $72.5 \%$ of the total production. The remaining $9.6 \%$ were distributed among the other countries as follows: $1.7 \%$ among 63 low-income countries, $5.4 \%$ among 54 lower middle-income countries and $2.5 \%$ among 31 upper middle-income countries. The upper middleincome countries had a smaller presence than did the lower middle-income countries. The five leading countries in the lower middle-income group (China, Russian Federation, Brazil, Turkey and South Africa) were responsible for $4.4 \%$ of the $5.4 \%$. If the proportion corresponding to production from India (which was among the low-income countries) is added to this $4.4 \%$, almost $6 \%$ of worldwide health-related research production is located in a small group of countries that includes Brazil. This group has been given the name of Innovative Developing Countries (IDCs). ${ }^{8}$

The health sector in Brazil today accounts for between $8 \%$ and $8.5 \%$ of the gross domestic product. In addition to a vast network of service providers, it incorporates an important industrial segment that is responsible for manufacturing medications, diagnostic devices, equipment, vaccines and blood derivatives. This segment uses technology intensively, with innovation, although these activities are predominantly developed outside of Brazil.

A survey on the funding for health-related research in Brazil carried out by Vianna et $\mathrm{a}^{12}$ showed that between 2003 and 2005, the mean annual expenditure on health-related research and development reached US\$

' Global Forum for Health Research. Financial flows in health research. Geneva; 2004 [cited 2008, Apr 8]. Available from: http://www. globalforumhealth.org/filesupld/monitorig_financial_flows2/MFF04chap0.pdf 
Table 3. Expenditure on health-related research and development, according to users. Brazil, 2003-2005.

\begin{tabular}{|c|c|c|c|c|c|}
\hline Source of funds $\mathrm{a}^{\mathbf{a}}$ & 2003 & 2004 & 2005 & 2003-2005 & Média Anual \\
\hline Federal government & 56.3 & 65.8 & 77.0 & 199.1 & 66.4 \\
\hline Ministry of Health & 50.8 & 55.0 & 66.7 & 172.5 & 57.5 \\
\hline Other ministries & 5.5 & 10.8 & 10.3 & 26.6 & 8.9 \\
\hline State and municipal governments & 21.6 & 25.0 & 26.8 & 73.4 & 24.5 \\
\hline Public sector & 77.9 & 90.8 & 103.8 & 272.5 & 90.8 \\
\hline Universities/research institutes & 450.5 & 487.3 & 552.5 & 1490.2 & 496.7 \\
\hline Private sector & 152.6 & 154.5 & 163.0 & 470.0 & 156.7 \\
\hline Pharmaceutical industry & 110.8 & 110.8 & 110.8 & 332.3 & 110.8 \\
\hline Equipment industry & 40.6 & 40.6 & 40.6 & 121.7 & 40.6 \\
\hline Other private institutions & 1.2 & 3.1 & 11.6 & 16.0 & 5.3 \\
\hline International organizations & 1.8 & 1.8 & 1.8 & 5.5 & 1.8 \\
\hline Total & 682.7 & 732.6 & 819.2 & 2234.5 & 744.8 \\
\hline
\end{tabular}

Source: Vianna et al ${ }^{12}$

${ }^{\mathbf{a}}$ Expenditure in United States dollars of 2000.

493.8 million in current dollars and US\$ 744.8 million when measured in dollars of 2000. This survey was conducted in accordance with the methodological standards of the Organization for Economic Cooperation and Development (Frascati/Oslo) and included all the universities and research institutes with health-related research activities, along with the Ministry of Health and the Ministry of Science and Technology (with their support agencies), and the Ministry of Education. It also included the main state agencies for research support (FAPESP, FAPEMIG and FAPERJ). The data relating to the private sector were extracted from PINTEC/IBGE. ${ }^{c}$ This sector was represented by the pharmaceutical industry and by the healthcare equipment industry.

The expenditure according to sources of funds, users and proportional flows between sources and users are presented in Tables 2 and 3 and in Figure 1. These show a situation that is very typical of IDCs, with four revealing characteristics of an immature national system for health-related innovation:

1) significant volume of financial resources destined for healthcare $R \& D$; 2) striking predominance of R\&D activities carried out in academic environments (the users of $66.7 \%$ of the financial resources were researchers in academic settings and in research institutes, mostly with an academic profile); 3) relatively small participation in health-related R\&D by the private industrial sector; 4) significant autochthonous capacity for R\&D funding, expressed as international financial resources of only $2.3 \%$ injected into the system.

Table 4 shows the distribution of financial resources from the public sector used for large items of expenditure, according to a similar survey conducted by the same team for the years 2000 and $2002 .{ }^{11}$

It can be seen that the salaries of researchers within health-related fields have significant weight within the funding situation (the great majority of them are teachers in higher education institutions $\mathrm{s}^{\mathrm{m}}$ ). In addition, for every real spent on supporting research projects, two reais are spent on study bursaries. It is likely that a situation with less imbalance has been established over recent years, given the large increase in financial resources for project support, in particular coming from the FNDCT and from new players within healthrelated research support and various state foundations for research support.

The most comprehensive information on the installed health-related research capacity in Brazil is available from the CNPq Research Group Directory, for which censuses have been conducted every two years since 2000. The key to identifying health-related research activities is the link to lines of research within the "human health" activity sector, as informed by the research group leader. This methodology has been used since $2001 .{ }^{6}$ According to this criterion, all the research groups that have at least one line associated with this sector, independent of the predominant field of knowledge of their activities, are conducting health-related research. Research groups within all major fields of knowledge have lines of research linked to the "human health" activity sector. The greatest number of these groups (around 50\%) belongs to health sciences and a little less than $25 \%$ to biological sciences. The remaining quarter belong to other major fields of knowledge.

${ }^{m}$ In Vianna's survey, establishing the expenditure on the critical mass within health research took into account the basic salaries of researchers participating in lines of research connected with the "human health" sector of activity in the census of the Directory of Brazilian Research Groups. 


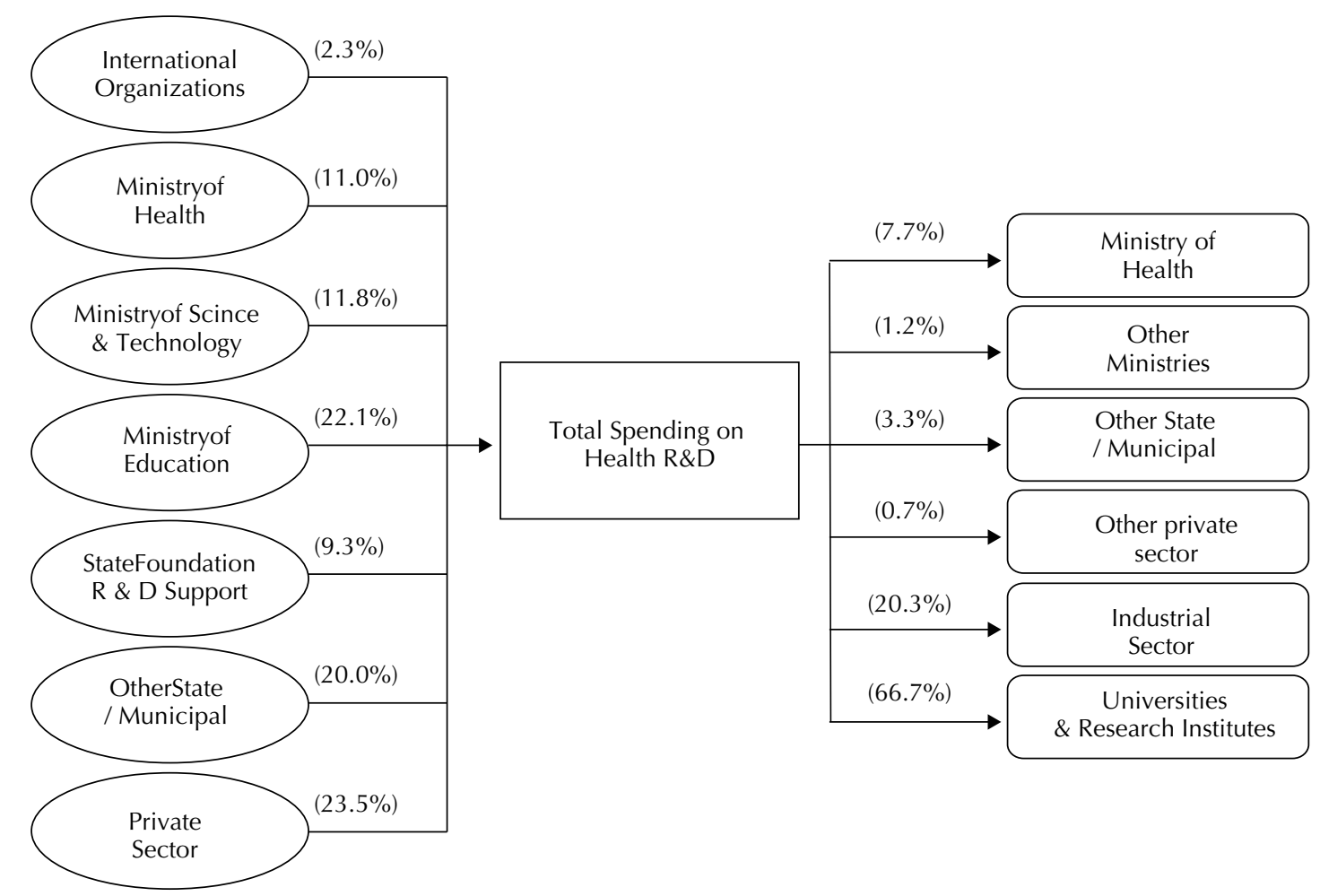

Source: Vianna et al $^{12}$

Figure 1. Proportional financial flow between sources and users of funds destined for health-related research. Brazil, 20032005.

Medicine is the predominant field in almost $20 \%$ of the groups that conduct health-related research, but there is large dispersion among other fields. There are lines of research on human health among research groups with predominant activities corresponding to 72 of the 75 fields in the CNPq tree. However, the 15 areas with greatest presence account for $71 \%$ of the groups.

Figure 2 shows the distribution of lines of research relating to human health according to the predominant fields of knowledge among the groups in which they are developed. Likewise, all the researchers with connections to lines of research associated with the human health sector are considered to form part of the critical mass involved with health-related research. Figure 3 presents the evolution in the number of lines of research on human health, in relation to the total number of lines of research between 2000 and 2008. According to data from the Directory, human health is the largest sector of research activity in Brazil in terms of installed capacity (number of lines of research) and critical mass (number of researchers involved).

Between 2000 and 2008, research activities on human health represented around $25 \%$ of all research activity in Brazil, without taking into account the research developed inside companies. In a general manner, health-related research increased pari passu with the overall total for research activities in this country.

The geographical distribution of health-related research activities follows the pattern of regional concentration that is observed overall for research activities in Brazil: $63 \%$ of the groups are located in the Southeastern region, $17 \%$ in the Southern region, $13 \%$ in the Northeastern region, $5 \%$ in the Central-western region and $2 \%$ in the Northern region.

Health-related research can be subdivided into four segments, namely: clinical, biomedical, technological and public health. Even though precise methodology for the distribution between these four segments still remains to be developed, a first approximation was attempted through rules to discriminate between the 18,351 lines that are linked to the human health activity sector: ${ }^{\mathrm{n}}$

- Clinical research incorporates all the lines of research in which the first link is to psychology, some lines relating to nutrition and some other lines relating to pharmacy; in addition, it incorporates all

${ }^{n}$ According to the methodology of the Directory of Research Groups, each line of research can be linked to up to three fields of knowledge. On the other hand, each research group only has one predominant field of knowledge in its activities. 


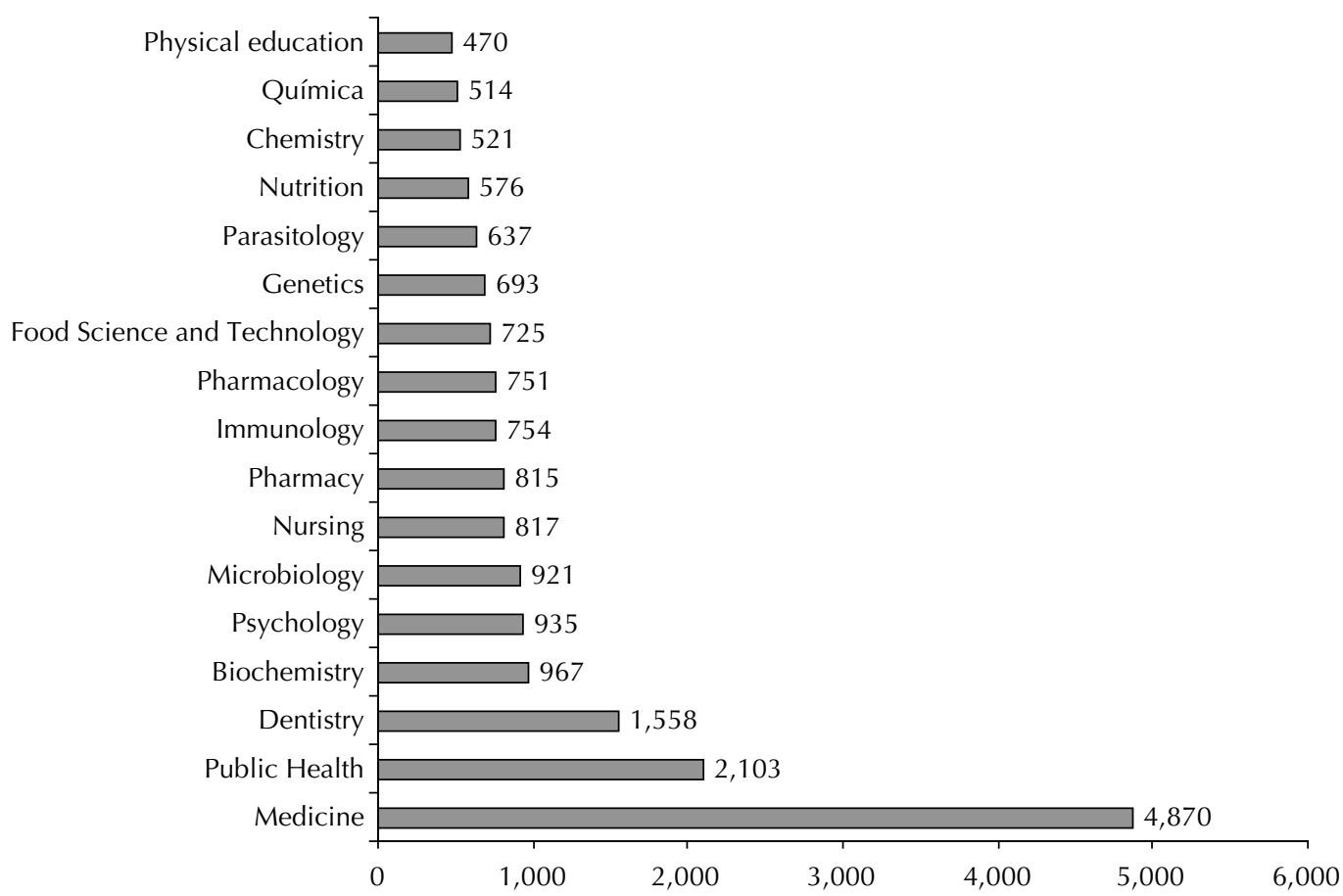

Source: CNPq Directory of Research Groups in Brazil and IBGE Census 2004

Figure 2. Human health-related lines of research according to the predominant fields of knowledge of the groups performing this research. Brazil, 2004.

lines in which the first link is to health sciences, except for public health;

- Biomedical research incorporates all the lines that are linked firstly to a major field of the biological sciences, along with some lines linked to pharmacy and nutrition;

- Public health research incorporates all the lines that are linked to public health, applied social sciences and human sciences, except for psychology;

- Health technology research incorporates the lines that are linked firstly to engineering and the exact sciences; in addition, it incorporates many lines that are linked to agrarian sciences and some lines of research that are linked to nutrition and pharmacy.

The results, extracted from the 2004 census of the Directory, are shown in Table 5. They show that clinical research predominated, accounting for almost half of the Brazilian healthcare efforts.

The concept of National Innovation Systems developed in Europe and the United States in the 1980s and 1990s, as part of the field of technology economics. They sought to comprehend the linkage processes among the very many players involved in new products and processes that appeared on the market, and in particular those that involved advanced scientific and technological knowledge. According to Albuquerque (1996), a National Innovation System is "an institutional construction that is the product from a deliberately planned action or from the sum of unplanned and disjointed decisions that propel technological progress in complex capitalist economies. Through constructing this innovation system, it becomes possible to achieve the information flows needed for the technological innovation process". ${ }^{2}$

The development of the concept was initially based on examining the leading economies around the world and was later on extended to more recently industrialized countries, including the IDCs. The concept has also more recently been extended to specific economic sectors (sectorial innovation systems). One of the characteristics of these sectorial systems is the presence of great heterogeneity in the innovation process between different sectors and even between subsectors within the sectors. ${ }^{\circ}$

In a general manner, the main focus of the studies is placed on the relationships between public and private players, with a view to economic development. The

${ }^{\circ}$ Gelijns A, Rosenberg N. The changing nature of medical technology development. In: Rosenberg N, Gelijns A. Dawkins H. Sources of medical technology: universities and industries. Washington: National Academy of Sciences; 1995 [cited 2008, Jul 14]. Available from: http:// nap.edu/catalog/4819.html 


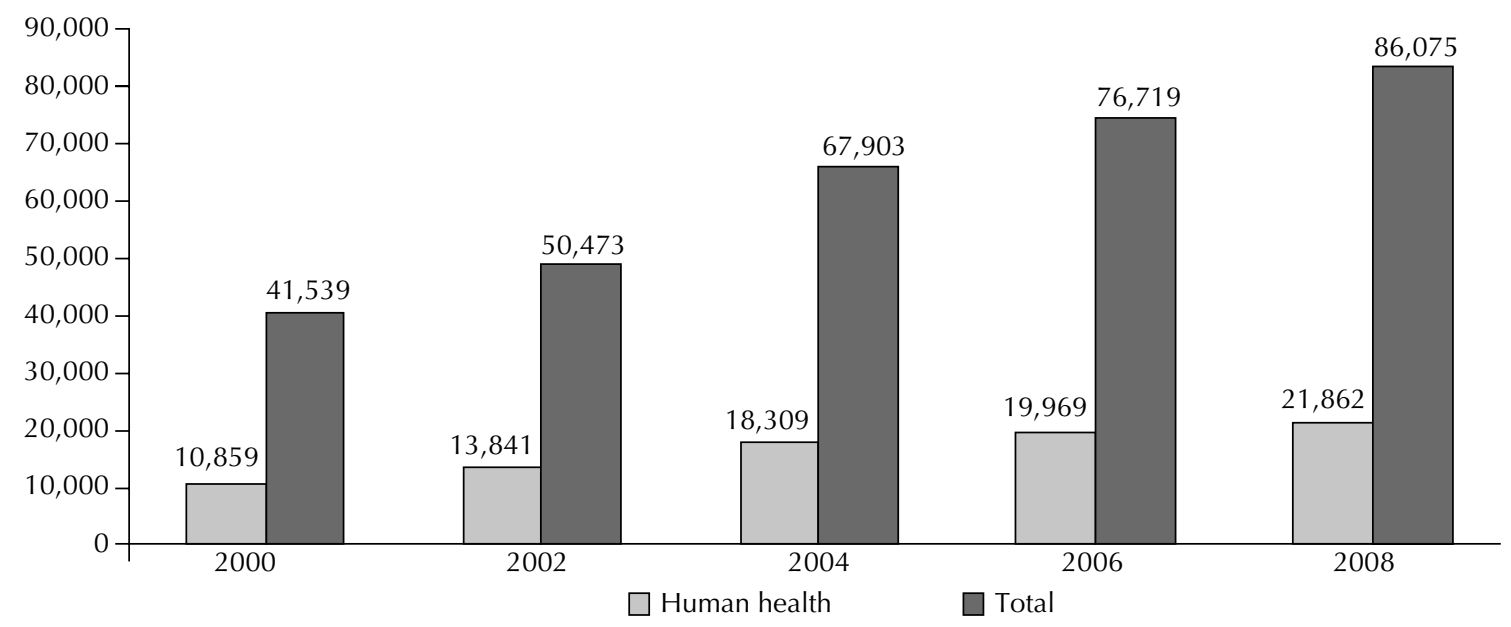

Source: CNPq Directory of Research Groups in Brazil

Figure 3. Human health-related lines of research in relation to the total number of lines of research. Brazil, 2000-2008.

linkage between national innovation systems and increased wellbeing and social inclusion is an area to be explored. In Brazil, Albuquerque et $\mathrm{al}^{2}$ discussed the possibilities within the field of healthcare of "combined construction of an innovation system and a social wellbeing system", ${ }^{1}$ while Gadelha et $\mathrm{al}^{4,5}$ coined and developed the concept of the healthcare production complex.

The main challenge for the field of R\&D on human health in Brazil relates to maturation of the healthrelated innovation system. Among other issues, this signifies recognizing the relevance of research that associates advancement of knowledge with consideration of early use of the results from such advances, i.e. through the type of investigation generically known as strategic research. In addition, this implies that companies should internalize the $R \& D$ procedures that today are predominantly conducted externally, and that the support mechanisms for these companies' R\&D activities from the federal and state governments (which are still at an incipient stage) should be expanded. Reinforcement of health-related research activities in universities and research institutes, through adjusting the priorities established by the healthcare system (in particular by its public component), and construction of bridges between these three worlds (companies, research institutes and healthcare system) that are more solid and permanent than those that currently exist, is fundamental to this process.

The importance of inputs of knowledge developed in research institutions for advancing the healthcare production complex is well known, and in particular, components of strongly technological nature such as medications, vaccines and diagnostic devices. The Innovation Law has opened wide paths towards establishing these bridges. On the other hand, the place for
Table 4. Annual mean expenditure on health-related research and development according to major items of expenditure. Brazil, 2000-2002.

\begin{tabular}{lcc}
\hline Item & US\$ million & $\%$ \\
\hline Total for public sector & 417 & 100 \\
Researchers' salaries & 232 & 55 \\
Training and productivity bursaries & 130 & 30 \\
Research support & 55 & 15 \\
\hline
\end{tabular}

Source: Vianna et al ${ }^{12}$

Table 5. Health-related research: distribution of lines of research according to segment. Brazil. 2004.

\begin{tabular}{lcc}
\hline Segment & Number of lines & $\%$ \\
\hline Clinical research & 8.586 & 46.8 \\
Biomedical research & 4,531 & 24.7 \\
Technological research & 2,781 & 15.2 \\
Public health research & 2,431 & 13.2 \\
Unclassified & 22 & 0.1 \\
\hline Total & 18,351 & 100.0 \\
\hline
\end{tabular}

Source: Directory of Research Groups in Brazil. at www.cnpq.br

innovation through excellence is in companies and, even with the recent political and legal advances, no significant results in terms of innovation have yet been observed from the use of support channels for R\&D projects that are directly linked to them (through BNDES, economic subsidies or FINEP). Moreover, as mentioned earlier, the health-related sectorial innovation system as an economic category (generating employment and income through production) needs to be linked to the health sector as a category for social inclusion (generating employment and income through increased wellbeing). 


\section{SOME CONCLUSIONS IN THE GUISE OF SUGGESTIONS}

The role of the postgraduate program policy within the human health sector over the coming years may be one of reinforcing the positive dimensions of the set of trends discussed in this text, and specifically, with adjustments in relation to the following:

1. Recognition of the growing role of extra-academic demands and players in the dynamics of training human resources for the market and, in particular, for research.

2. Action in synergy with the movement towards maturation of the health-related sectorial innovation system, which includes a more attentive look not only at the human resource needs for technological development and innovation in companies but also at the challenge of solidly linking postgraduate programs with the priorities of the National Health System (research and service priorities).

3. Contribution towards healthy maturation of the institutional models that have recently been placed within the scenario of Brazilian research, with clearer expression in the national science and technology institutions and in centers for research, innovation and dissemination in which the human health sector sets the pace.

4. Adaptation of the methodology of the traditional and exemplary CAPES assessment process regarding these trends, which in a general manner will mean adding new indicators for technological and social productivity, to the existing predominantly academic criteria.

5. With regard to assessments, revision of the theoretical-methodological and disciplinary concepts that govern the profiles of the fields, with some space conceded in these profiles to considerations of a teleological (finalistic) nature.

6. Continuation and deepening of the initiatives that are in progress towards admitting new formats for postgraduate programs and courses, among others, with customization to the demands of the extra-academic market, either of social or of technological-business nature.

7. Deepening of the initiatives already in progress, such that CAPES should accept that there is a shortage of postdoctoral training in Brazil that should be a focus for its actions.

\section{REFERENCES}

1. Albuquerque EM, Souza SGA, Baessa AR. Pesquisa e inovação em saúde: uma discussão a partir da literatura sobre economia da tecnologia. Cienc Saude Coletiva. 2004;9(2):277-94. DOI:10.1590/S141381232004000200007

2. Albuquerque EM. Sistema nacional de inovação no Brasil: uma análise introdutória a partir de dados disponíveis sobre a ciência e a tecnologia. Rev Econ Politica. 1996;16(3):56-72.

3. Gadelha CAG. O complexo industrial da saúde e a necessidade de um enfoque dinâmico na economia da saúde. Cienc Saude Coletiva.2003;8(2):521-35. DOI:10.1590/S1413-81232003000200015

4. Gadelha CAG, Quental C, Fialho BC. Saúde e inovação: uma abordagem sistêmica das indústrias da saúde. Cad Saude Publica.2003;19(1):47-59. DOI:10.1590/S0102-311X2003000100006

5. Guimarães R. FNDCT: uma nova missão. In: Schwartzman S. Ciência e Tecnologia no Brasil: política industrial, mercado de trabalho e instituições de apoio. Rio de Janeiro: Editora da Fundação Getúlio Vargas; 1995. p. 257-87.

6. Guimarães R, Lourenço RE, Cosac S. A pesquisa em epidemiologia no Brasil. Rev Saude Publica. 2001;35(4):321-40. DOI:10.1590/S003489102001000400001
7. Guimarães R, Lourenço R, Cosac S. Os pesquisadores: perfil dos doutores em pesquisa no Brasil. Brasília: Parcerias Estratégicas; 2001. p.122-50.

8. Morel C, Acharya T, Broun D, Dangi A, Elias C, Ganguly NK, et al. Health innovation networks to help developing countries address neglected diseases. Science. 2005;309(5733):401-4. DOI:10.1126/ science. 1115538

9. Paraje G, Sadana R, Karam G. Increasing international gaps in health related publications. Science. 2005;308(5724):959-60. DOI:10.1126/ science. 1108705

10. Stokes DE. O Quadrante de Pasteur: a ciência básica e a inovação tecnológica. Campinas: Editora da Unicamp; 2005

11. Vianna CMM, Caetano R, Ortega JA, Façanha LOF, Gonzalez Mosegui GB, Siqueira M, et al. Flows of financial resources for health research and development in Brazil, 2000-2002. Bull World Health Organ. 2007;85(2):124-30. DOI:10.1590/S004296862007000200010

12. Vianna CMM, Caetano R, Mendes da Silva R, Sampaio MMA, Rodrigues RRD. Brazil: Financing Resource Flows in Health R\&D. In: Landriault E, Matlin SA, editors. Genvea: Global Forum for Health Research, Monitoring Financial Flows for Health Research; 2009. p.129-35.

The author declares that there are no conflicts of interest. 